\title{
Manejo de Ralstonia Solanacearum raza 2 a través de productos químicos y biológicos
}

\section{Management of Ralstonia Solanacearum race 2 through chemical and biological products}

\author{
Celina Torres-González \\ M.Sc. Ingeniero Agrónomo, Docente tiempo completo, \\ Investigador Grupo Biología Vegetal y Microorganismos, \\ Universidad del Valle, Colombia \\ cetorres@correounivalle.edu.co
}

\author{
Mauricio Casas \\ M.Sc. Biología, Investigador Grupo Biología Vegetal y \\ Microorganismos, Universidad del Valle, Colombia \\ Mauricio.casas@univalle.edu.co
}

\author{
Jaime Ernesto Díaz Ortiz \\ Ph.D. Ingeniería Agrícola, Docente tiempo completo, Investigador \\ Grupo Biología Vegetal y Microorganismos, \\ Universidad del Valle, Colombia \\ Jaime.diaz@correounivalle.edu.co
}

\begin{abstract}
Resumen- Determinar métodos eficaces que ayuden al manejo y erradicación de la marchitez bacteriana, en el Parque Nacional de las Heliconias, localizado en el municipio de Caicedonia, se recolectaron muestras de heliconia con síntomas de marchitez bacteriana. Se identificó a Ralstonia solanacearum Raza 2, Como causante de la enfermedad. Para evaluar la capacidad de control en el crecimiento bacteriano se empleó un diseño experimental con 1 factor y 4 tratamientos, mediante extracto de Toronja, Bacillus subtilis, hidróxido de cobre y extracto acuoso de Swinglea (Swinglea glutinosa). La efectividad de control de la bacteria in vitro se presentó de mayor a menor en el siguiente orden: hidróxido de cobre (100\%), Subtilin (92\%) y extracto de toronja (36\%). El extracto acuoso de Swinglea no presentó efectos inhibitorios.
\end{abstract}

Palabras clave- Control biológico, Ralstonia solanacearum Raza 2.

Abstract- To determine effective methods to help the management and eradication of bacterial wilt at Heliconias National Park, located in Caicedonia municipality, heliconia's samples with symptoms of bacterial wilt were collected. Ralstonia solanacearum Race 2 was identified as the cause of the disease. The experimental design for assessing bacterial growth was conducted with a factor and four treatments. For treatments was used Grapefruit extract, Bacillus subtilis, copper hydroxide and aqueous extract Swinglea (Swinglea glutinosa). The most effective control of bacteria in vitro was presented in the following order: copper hydroxide (100\%), subtilin (92\%) and grapefruit extract (36\%). The Extract Swinglea glutinosa did not show any inhibitory effect.

Keywords- Bio-control, Ralstonia solanacearum Race 2.

\section{INTRODUCCIÓN}

La marchitez bacteriana, causada por Ralstonia solanacearum Raza 2, es una enfermedad cuyo manejo fitosanitario se fundamenta en el empleo de métodos químicos que pueden ser nocivos para el medio ambiente y el hombre. Existen procedimientos para su manejo y erradicación que se han mostrado poco eficaces en el control de la misma en los cultivos de heliconia.

La familia Heliconiaceae incluye hierbas perennes, rizomatosas, con patrón de colonización vegetativa y vástagos que varían según la especie, la inflorescencia es terminal péndula o erecta, coleada y vistosa. Estas especies neo-tropicales se encuentran distribuidas desde México hasta Argentina e islas del Caribe y muchas son cultivadas como plantas ornamentales [1].

Anteriormente, las heliconias que habían sido clasificadas en la familia Musaceae (plátano y banano); en 1941 Nakai las separó en la familia Heliconiaceae y posteriormente por [2], quienes propusieron un nuevo sistema de clasificación en subgéneros y secciones, basado en características morfológicas, ecológicas y genéticas, pero esta diferenciación no significó condiciones diferenciadas para ser inmune a enfermedades que afectan al plátano y al banano [3]. 
La enfermedad conocida como Moko, es ocasionada por la bacteria Ralstonia solanacearum; se clasifica en cinco razas, la raza 2 es la causante de la misma, y afecta a las familias Musaceae y Heliconiaceae y produce problemas fitosanitarios como detención del crecimiento, clorosis, necrosis y doblamiento foliar en especial de la hoja bandera, obstrucción de los haces vasculares, pudrición del rizoma y raíz, todos ellos que inciden en el desarrollo del cultivo [4]. En regiones en las que aún no se ha detectado su presencia representa un problema potencial [5]. La diseminación de $R$. solanacearum es favorecida por condiciones relacionadas con el medio (suelo, agua, aire), los insectos, las semillas infectadas y medidas fitosanitarias poco eficientes.

En Colombia, la enfermedad se reportó por primera vez en 1954 en los municipios de Prado y Purificación del Tolima [6] y en la zona bananera de Urabá, zona sur del municipio de Carepa en 1999 (Mena) [7]. Durante la década del setenta su incidencia ocasionó pérdidas económicas, en el departamento del Caquetá, donde fueron afectadas 20.000 hectáreas de plátano y banano [8]. En la zona platanera del departamento del Quindío, las pérdidas económicas producidas durante el año 2000, fueron valoradas en US $\$ 78.000$ [9]. Estudios realizados por el Instituto Colombiano Agropecuario (ICA) mostraron que las pérdidas económicas ocasionadas por esta enfermedad ascendieron en dos años a la suma de US $\$ 985.000$ [10]. La enfermedad se ha convertido en una amenaza para los cultivos de exportación en la zona del Caribe colombiano y para aquellos establecidos en la zona cafetera central [1].

Granada [11]-[13], realizó pruebas moleculares para tipificar el microorganismo causante de Moko, considera que la alta incidencia de la enfermedad en las zonas bananeras y plataneras del país, está relacionada con mutaciones de la bacteria hacia linajes más virulentos. La variabilidad de 28 aislamientos, mediante la técnica de RFLPs (Polimorfismo de longitud de fragmentos), fue estudiada en nueve departamentos de Colombia. Se encontraron cuatro genotipos de locus múltiples: (MLGs, 25 - 47 - 48 y 51). Existen más de 187 especies vegetales hospedantes de la bacteria y en el departamento del Quindío, se ha observado que el genotipo MLG25 puede sobrevivir durante seis meses en los tejidos de las plantas y en el suelo [14]. Con base en los resultados anteriores esta investigación se concentró en buscar métodos de control eficientes.

Las investigaciones realizadas para hallar un método eficaz de manejo de la enfermedad se han enfocado principalmente a especies parentales de las heliconias (plátano y banano), razón por la cual la gran mayoría de referencias relacionadas con estudios en $R$. solanacearum raza 2 corresponden a estos cultivos. En ocasiones se ha utilizado inyecciones periódicas con soluciones de glifosato al 15\% (N-fosfonometilglicina) para erradicar plantas afectadas por Moko. La escasez de información sobre métodos de manejo fitosanitario en plantaciones de especies pertenecientes a la familia Heliconiaceae, condujo a la realización de este estudio que evaluó métodos químicos y biológicos para el manejo de $R$. solanacearum raza 2 , con el fin de verificar una reducción del patógeno in vivo.

En la práctica las enfermedades son controladas con productos químicos con base en hidróxido de cobre; sin embargo, es necesario buscar otras alternativas para el control que sean amigables con el ambiente. En el presente estudio se evaluaron productos químicos y biológicos como el extracto de S. glutinosa, reportado por el Centro Interamericano de Agricultura Tropical (CIAT) para el manejo de Antracnosis de fríjol (Glomerella lindemuthiana o Colletotrichum lindemuthianum (anamorfo)), el Mildeo polvoso de la rosa (Sphaerotheca pannosa) y la Roya en café (Hemileia vastatrix) [15]. También se empleó el extracto de toronja, debido a su actividad bactericida y fungicida, que actúa sistémicamente en la planta, dañando la pared celular y el citoplasma en el hongo patógeno impidiendo su multiplicación [16]. Igualmente, se aplicó la bacteria Bacillus subtilis como control biológico aunque esta no es usada en diversas patologías por su capacidad de producir metabolitos secundarios.

\section{MATERIALES Y MÉTODOS}

La investigación se dividió en tres fases: campo, invernadero y laboratorio. La fase de campo se realizó en el Centro de Educación Ambiental y Desarrollo Agroecoturístico del Parque Nacional de las Heliconias, localizado en el municipio de Caicedonia departamento del Valle del Cauca, 
que cuenta con una temperatura promedio de $23^{\circ} \mathrm{C}$ y una altura que varía entre 1.050 y 2.200 msnm. El muestreo se realizó en un área de 5,6 ha, en las que se encuentran aproximadamente 160 cultivares de heliconias. Se delimitaron cinco parcelas de $88 \mathrm{~m}^{2}$ cada una con, 22 individuos, seleccionadas al azar, que mostraban síntomas de marchitez bacteriana. Las pruebas de laboratorio se realizaron en la unidad de investigaciones microbiológicas (UIM), del Departamento de Biología de la Universidad del Valle.

En la fase de campo se evaluó la incidencia y severidad de la enfermedad y se colectaron muestras de tallos, hojas y flores que presentaron síntomas de la enfermedad, los cuales se llevaron a la unidad de Investigaciones Microbiológicas, con el propósito de aislar y purificar la bacteria causante del marchitamiento ( $R$. solanacearum raza 2). Para el aislamiento de la bacteria se tomaron muestras con síntomas de la enfermedad que se cortaron en trozos de $5 \mathrm{~mm}^{2}$ y se sumergieron en alcohol al 96\%, posteriormente en Hipoclorito de Sodio al $0.5 \%$ y se lavaron con agua destilada estéril, por 30 segundos para cada paso. Los trozos se maceraron en agua destilada estéril y se sembraron por el método de estría simple en cinco cajas Petri con Agar nutritivo (dextrosa-10 g, peptona-10 g, cas-aminoácidos-1 g L $\mathrm{L}^{-1}$ de agua) y se dejaron en incubadora a $28^{\circ} \mathrm{C}$. Para garantizar la pureza del proceso se realizaron aislamientos dobles.

Para verificar cuál de las bacterias aisladas correspondía a $R$. solanacearum Raza 2, se realizaron pruebas morfológicas y bioquímicas como coloración de Gram, gránulos de poly-B-hydroxybutirato, hidróxido de potasio $(\mathrm{KOH})$ al 3\%, oxidación de glucosa, oxidasa, catalasa, hidrólisis o licuefacción de gelatina, Citrato de Simmons, hidrólisis de almidón, reducción de nitratos, arginina di-hidrolasa y se determinó la tolerancia a soluciones de $\mathrm{NaCl}$ al $0.5 \%$ y $2 \%$.

\subsection{Pruebas de patogenicidad con la bacteria R. solanacearum}

Con base en las pruebas morfológicas y bioquímicas, se seleccionó la bacteria para realizar las pruebas de patogenicidad y verificar si el aislamiento de R. solanacearum Raza 2, era el causante de los síntomas de la enfermedad. De acuerdo con [17], se realizó una dilución de la bacteria en $1 \mathrm{ml}$ de agua destilada estéril en una concentración de $1 \times 10^{5}$ células bacterianas $/ \mathrm{ml}$. de la solución resultante se aplicaron $0.25 \mathrm{ml}$. de inóculo a cada planta por el método de punción. Se inocularon en invernadero treinta plantas de heliconia; diez para cada cultivar (Heliconia Wagneriana, Heliconia bihai Heliconia Latisphata).

Las plantas inoculadas se evaluaron a partir del quinto día cada 24 horas durante un periodo de veintiún días o hasta la aparición de síntomas similares a los detectados en campo (manchas redondeadas de color café, ampollas en las hojas, secreción de moco o fluido viscoso en tallo).

\subsection{Evaluación in Vitro de tratamientos Biológicos}

La evaluación in vitro se efectuó con concentraciones inhibitorias de un extracto vegetal (Swinglea glutinosa), dos productos biológicos (PD-1000 a base de extracto de toronja y Subtilin) y un producto de origen químico (Kocide) a base de hidróxido de cobre (53.8\%).

Para obtener el extracto de S. glutinosa se secaron durante cinco días en condiciones ambientales (temperatura $<40^{\circ} \mathrm{C}$ y sombrío), 100 $g$ del follaje de la planta, a los cuales se extrajo el extracto con etanol a $96 \%$ empleando Soxhlet durante una hora. Las dosis de cada producto se presentan en la Tabla I.

Para evaluar el crecimiento del patógeno, se sembró la bacteria R. solanacearum Raza 2 en cajas Petri con Agar Nutritivo (AN), para las tres concentraciones con repeticiones de cada producto (Tabla I). La medición se inició a los 2 días de la siembra, tomando como patrón de referencia el $100 \%$ del crecimiento en el control.

\subsection{Diseño experimental}

Se trabajó con diseño experimental de dos factores: el primero correspondiente a los productos empleados (P1, P2, P3, P4) y el segundo a las distintas concentraciones de los productos (LD-25, LD-50 y LD-100). Se realizaron tres repeticiones por cada tratamiento con sus controles respectivos. Se denominó concentración normal (LD-50), a la dosis recomendada por el fabricante, (LD-25) a la mitad y (LD-100) al doble de la recomendada. En el caso de la preparación con el extracto 
vegetal acuoso de Swinglea glutinosa, las concentraciones se diluyeron en alcohol al 70\% así, para (LD-25, 2.5ml), (LD-50, $5 \mathrm{ml}$ ), (LD-100, $10 \mathrm{ml}$ ) de acuerdo con el protocolo descrito por [15]. La variable de respuesta fue el crecimiento de $R$. solanacearum. El crecimiento celular obtenido en las fases in vitro e in vivo se analizó con Anova, con pruebas de Tukey y mediante determinaciones no paramétricas (Kruskall-Wallis y Nemenyi).

Se empleó el método de difusión aplicado a cajas Petri, $5 \mathrm{~cm}^{3}$ de los diferentes productos biológicos en sus distintas concentraciones (Tabla I). Posteriormente se adicionó como medio de cultivo agar nutritivo con $5 \%$ de sucrosa; la bacteria $(R$. solanacearun) se sembró por estría en superficie. A partir del segundo día de inoculación y durante cinco días se empleó el método de medición directa por microscopio, para evaluar su crecimiento en términos del número de células.

\subsection{Control in vivo de R. solanacearum}

Para evaluar los productos biológicos in vivo se realizaron dos tratamientos: planta con bacteria sin producto y planta con bacteria y producto. Como testigo se utilizaron plantas sin bacteria ni producto. Cada tratamiento tuvo tres repeticiones por cada producto $(\mathrm{P})$, a diferentes concentraciones (LD). El producto se aplicó empleando el método de punción.

\section{RESULTADOS Y DISCUSIÓN}

La evaluación de la incidencia en campo de la marchitez bacteriana en cultivares de Heliconias, mostró un promedio de $90 \%$ de plantas enfermas en cada parcela. En el laboratorio, Ios aislamien- tos bacterianos obtenidos del material vegetal enfermo correspondieron a la bacteria $R$. solanacearum, lo cual se corroboró mediante pruebas morfológicas y bioquímicas. La bacteria se caracteriza por formar colonias de aspecto mucoide debido a su abundante producción de polisacáridos como puede verse en la Fig. 1.

Microscópicamente se observa como un bacilo móvil, con coloración rosa obtenido con fucsina en la tinción de Gram que junto con el resultado positivo de la prueba de $\mathrm{KOH}$ al 3\%, determinan que es una bacteria gram negativa. Los resultados de las pruebas bioquímicas más relevantes se muestran en la Tabla II, que determina a R. solanacearum como una bacteria aeróbica estricta con catalasa positiva, con reducción de nitratos, producción de ácido a partir de disacáridos y oxidación de alcoholes, estos resultados coinciden con lo reportado en [18].

Fig. 1. CEPA PURA DE RALSTONIA SOLANACEARUM RAZA 2 EN MEDIO AGAR NUTRITIVO

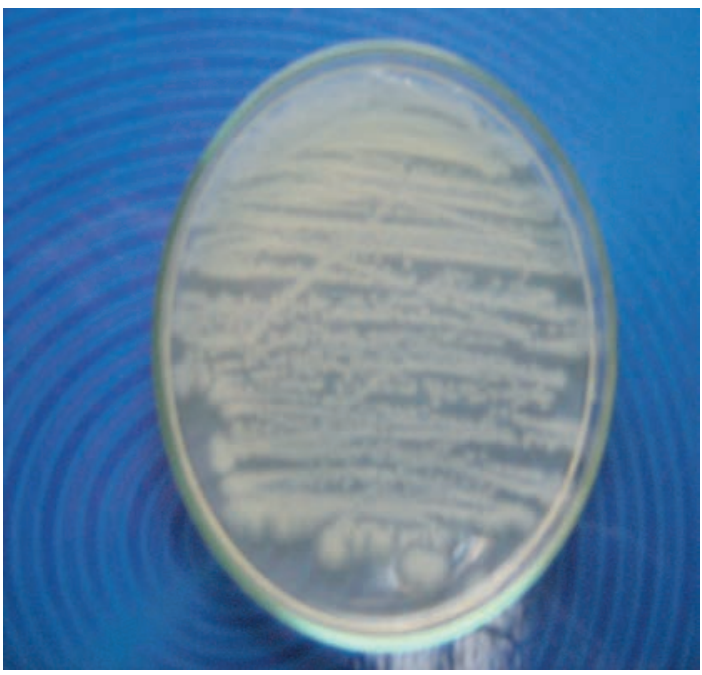

TABLA I

DOSIS DE CADA PRODUCTO EVALUADO A NIVEL IN VITRO PARA EL CONTROL DE R. SOLANACEARUM

\begin{tabular}{cccc}
\hline \multirow{2}{*}{ Producto } & \multicolumn{3}{c}{ Concentración } \\
\cline { 2 - 4 } & LD25 & LD50 & LD100 \\
\hline Extracto de S. glutinosa & $7.5 \mathrm{~mL} / \mathrm{L}$ de AN & $15 \mathrm{~mL} / \mathrm{L}$ de AN & $30 \mathrm{~mL} / \mathrm{L}$ de AN \\
Extracto de toronja & $2.5 \mathrm{~mL} / \mathrm{L}$ de AN & $5 \mathrm{~mL} / \mathrm{L}$ de AN & $10 \mathrm{~mL} / \mathrm{L}$ de AN \\
Bacillus subtilis & $1 \mathrm{~g} / \mathrm{L}$ de AN & $2 \mathrm{~g} / \mathrm{L}$ de AN & $4 \mathrm{~g} / \mathrm{L}$ de AN \\
Hidróxido de cobre & $0.025 \mathrm{~g} / \mathrm{L}$ de AN & $0.05 \mathrm{~g} / \mathrm{L}$ de AN & $0.1 \mathrm{~g} / \mathrm{L}$ de AN \\
\hline
\end{tabular}


TABLA II

CARACTERÍSTICAS FISIOLÓGICAS DE R. SOLANACEARUM

\begin{tabular}{|l|c|}
\hline \multicolumn{1}{|c|}{ PRUEBA } & Resultado \\
\hline Gránulos de Poly-B-hydroxybutirato & + \\
\hline Oxidación de glucosa & + \\
\hline Oxidasa & - \\
\hline Tolerancia a soluciones de NaCl al 0,5\% & - \\
\hline Tolerancia a soluciones de $\mathrm{NaCl}$ al 2\% & + \\
\hline Catalasa & - \\
\hline Hidrólisis o licuefacción de gelatina & + \\
\hline Simmons citrato & - \\
\hline Hidrólisis de almidón & + \\
\hline Reducción de nitratos & + \\
\hline Arginina dihidrolasa. & + \\
\hline
\end{tabular}

Las resultados de las pruebas de patogenicidad para verificar si el aislamiento de $R$. solanacearum era el agente causante del marchitamiento bacteriano (Moko) en heliconias, mostraron que a los 45 días después de la inoculación de la bacteria en plantas sanas se replicaron los síntomas de la enfermedad observados en campo: manchas redondeadas de color marrón, ampollas en las hojas, secreción de moko o fluido viscoso en el tallo. Lo que permitió identificar a la bacteria como el agente causante de Moko en los cultivares de Heliconias estudiados (Fig. 2).

FIG. 2. SÍNTOMAS OBSERVADOS EN LAS PLANTAS INOCULADAS CON LA BACTERIA RALSTONIA SOLANACEARUM

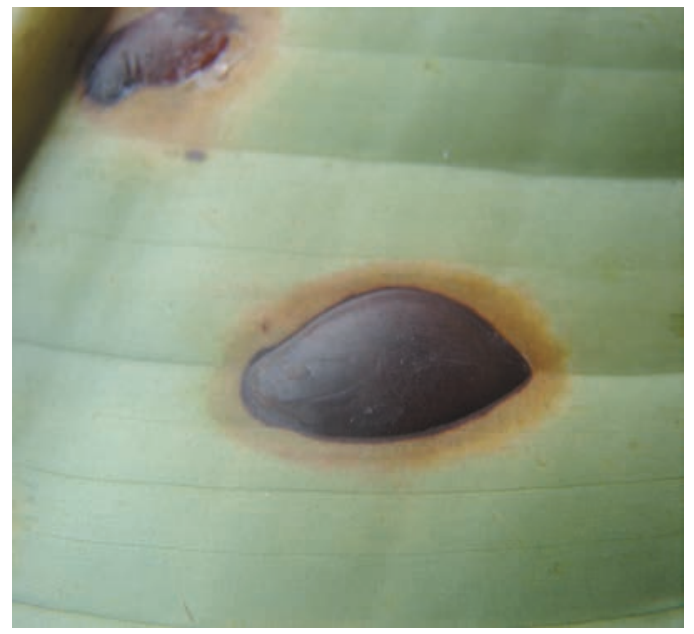

Una vez confirmada la patogenicidad de $R$. solanacearum se realizaron las pruebas in vitro para evaluar la eficiencia de los cuatro productos sobre el control de la bacteria. En la Tabla III se muestra el promedio del porcentaje de crecimiento de la bacteria en las tres réplicas para cada tratamien- to, se observó que después de 21 días de seguimiento del crecimiento de la bacteria, el hidróxido de cobre en todas las dosis evaluadas fue el tratamiento más efectivo para el control, seguido de B. subtilis y el extracto de toronja. El extracto de S. glutinosa no presentó diferencias significativas con respecto al testigo.

TABLA III

EFECTO DE CUATRO PRODUCTOS CON TRES DOSIS SOBRE EL CRECIMIENTO EN PORCENTAJE DE LA BACTERIA R. SOLANACEARUM

\begin{tabular}{|c|c|c|c|c|}
\hline \multirow{2}{*}{ Dosis } & \multicolumn{4}{|c|}{ Tratamientos } \\
\cline { 2 - 5 } & $\begin{array}{c}\text { Extracto } \\
\text { de Toronja }\end{array}$ & B. subtilis & $\begin{array}{c}\text { Extracto de } \\
\text { S. glutinosa }\end{array}$ & $\begin{array}{c}\text { Hidróxido } \\
\text { de Cobre }\end{array}$ \\
\hline LD-25 & 69 & 8,7 & 97,7 & 0 \\
\hline LD-50 & 42,7 & 4,7 & 97,3 & 0 \\
\hline LD100 & 10,3 & 3,3 & 98,7 & 0 \\
\hline CONTROL & 100 & 100 & 100 & 100 \\
\hline
\end{tabular}

Para determinar la existencia de diferencias significativas entre los resultados obtenidos en cada uno de los tratamientos con sus respectivas dosis se aplicó un análisis de varianza. El crecimiento bacteriano con el extracto de toronja mostró una distribución normal (Prueba Kolmogorov-Smirnov) y el análisis de varianza entre los tratamientos (LD) indicó diferencias significativas. La prueba de Tukey señaló que las dosis LD-50 y LD 100 disminuyeron el crecimiento de $R$. solanacearum esta última presentó mayor efectividad en el control de la bacteria ya que disminuyó su crecimiento en un $80 \%$, como se muestra en la Fig. 3. En la Fig. 3, se indica el efecto de inhibición del crecimiento causado con la dosis LD 100 de extracto de toronja, frente al que se encontró con el control. La disminución de crecimiento de la bacteria por este producto puede deberse a los componentes del producto: extracto de toronja, cumarinas, metoxiflavonas, flavonas y otras sustancias que actúan como antibióticos [14], además el producto PD 1000 también se compone de sustancias ácidas como el ácido ascórbico que disminuye el pH del medio e inhiben el crecimiento.

Para el análisis de los datos obtenidos con $B$. subtilis, se aplicó la prueba de Kruskall-Wallis, que no detectó diferencias significativas entre los tratamientos (LD), debido quizás a que su efecto antibacteriano fue similar en todas las dosis (Fig. 4). La prueba de Nemenyi indicó que las dosis LD25 y LD-50 fueron las más efectivas en reducir el crecimiento de la bacteria $(p<0.05)$, se confirma 
que este producto es eficaz para el control del patógeno. Esto puede atribuirse a la acción del ingrediente activo en cepas certificadas de BaciIlus subtilis, cuya actividad bactericida natural la convierte en agente de control biológico que produce un antibiótico llamado subtilin, impidiendo el desarrollo de bacterias Gram positivas y negativas, al alterar la permeabilidad de la membrana celular e inhibir el paso de potasio y el transporte de ATP [19].

Fig. 3 CONTROL INHIBITORIO DE LA BACTERIA RALSTONIA SOLANACEARUM RAZA 2 CON PD-1000 FRENTE AL CONTROL
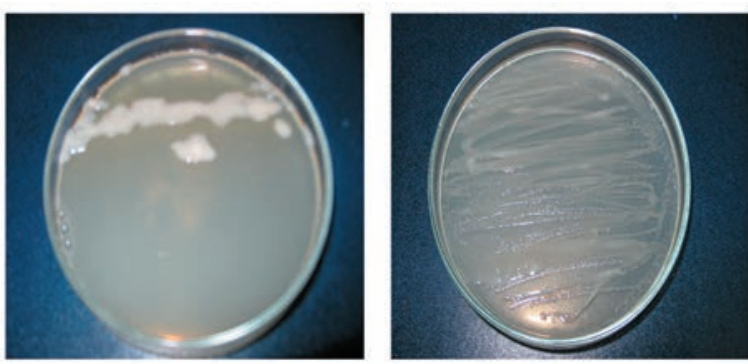

El análisis con la prueba Kolmogorov-Smirnov del crecimiento bacteriano en los medios con extracto vegetal acuoso de S. glutinosa, indicó una distribución normal sin diferencias significativas $(p>0,05)$ entre sus tratamientos como se observa en la Fig. 4.

FIG. 4. CRECIMIENTO EN PORCENTAJE DE LA BACTERIA RALSTONIA SOLANACEARUM RAZA 2 CON SUBTILIN

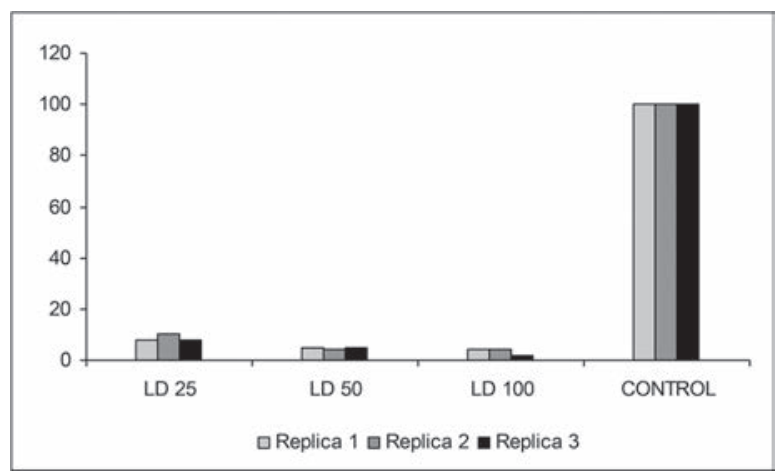

Para el análisis de los resultados de hidróxido de cobre, se aplicó la prueba de Kruskall-Wallis (distribución asimétrica), que no mostró diferencias significativas con respecto al control, debido a que en todas las dosis se inhibió por completo el crecimiento de la bacteria. El resultado anterior se puede atribuir al efecto ejercido por el sulfato cúprico básico, que es el agente activo del producto tal como se muestra en [20]. El cobre inactiva la mayoría de enzimas y coenzimas, desnaturalizan- do proteínas y dañando el metabolismo del patógeno. Además, dicho agente crea las condiciones para que el medio tome un $\mathrm{pH}$ básico, poco propicio para el crecimiento bacteriano. (http://hgic. clemson.edu/PDF/uga4s.pdf, 2012).

Sin embargo, el constante empleo de este producto puede ser nocivo para el ambiente por lo que es necesario buscar otras alternativas para el control de la bacteria.

Según el análisis de Kruskall-Wallis, la comparación entre los diferentes productos con respecto a su efectividad inhibitoria, mostró diferencias significativas entre estos. La prueba de Nemenyi, indicó que el producto de mayor eficacia fue el hidróxido de cobre, mostrando diferencias significativas frente al extracto de S. glutinosa, toronja y los testigos $(P \leq 0.05)$. Sin embargo, la prueba no mostró diferencias significativas con $B$. subtilis y PD-1000, demostrando que estos dos últimos productos biológicos pueden ser altamente efectivos para el control de la bacteria in vitro (Ver Fig. 5).

Fig.5. CONTROL INHIBITORIO DE LA BACTERIA RALSTONIA SOLANACEARUM RAZA 2 EN SUBTILIN FRENTE AL CONTROL


\section{CONCLUSIONES}

El producto que presentó mayor efecto inhibitorio en el crecimiento de Ralstonia solanacearum Raza 2, fue el compuesto con base de hidróxido de cobre.

Los productos a base de extracto de toronja y B. subtilis, mostraron efecto inhibitorio significativo sobre el crecimiento de Ralstonia solanacearum Raza 2, presentando pocas diferencias con el hidróxido de cobre.

El producto con base de extracto acuoso de Swinglea glutinosa, no presentó ningún tipo de efecto inhibitorio en el crecimiento de Ralstonia solanacearum Raza 2. 
Los productos biológicos B. subtilis y PD 1000 son una excelente alternativa para iniciar un programa fitosanitario de los cultivares de Heliconias afectadas por la marchitez bacteriana (Moko), ocasionado por la bacteria Ralstonia solanacearum Raza 2.

\section{REFERENCIAS}

[1] J. Pinzón.. El cultivo de las heliconias y las flores tropicales, nueva opción de exportación, Trans. Plasma Sci. [Online]. vol 21 no 3, pp. 876-880. 2006 Disponible en: http://heliconias.galeon.com

[2] W. Krees, J. Betancur and B. Echeverri, Heliconias llamaradas de la selva Colombiana, Guía de Campo. Cristina Uribe Editores Ltda., Bogotá, 2006.

[3] C. Bustamante, "La zonificación ambiental como estrategia para la planificación de los sistemas agroforestales y la recuperación y conservación de los recursos naturales", Programa Nacional de Agroecosistemas, Centro Experimental Tibaitatá, Corpoica, Colombia, 1999.

[4] J. Alarcón, and M. Bernal, "El cultivo de heliconias medidas para la temporada invernal," Produmedios, ICA Bogotá, pp. 21-24. Apr. 2012.

[5] A. Arenas, D. López, G. Lano, E. Álvarez and J. Loke, "Efecto de las prácticas ecológicas sobre la población de Ralstonia solanacearum Smith., causante de Moko de Plátano," XXV Congreso ASCOLFI, Cali, 2004

[6] Buddenhagen, I.W, "Moko disease", en Compendium of tropical fruit diseases, G.A. Ploetz, R.C. Zentmyer, W.T. Nishijima, K.G. Rohrbach and H.D. Ohr, Ed. APS Press, 1994a.

[7] J. Mena, "Programa de sanidad vegetal de Augura," Carta Informativa, vol. 208, no.3, pp. 12-13, Apr. 1999.

[8] E. S. De Oliveira, “Evaluación de Musa spp., para la resistencia a la enfermedad del Moko (Ralstonia solanacearum Raza \# 2)," Infomusa, vol. 9, No.1, pp. 19-20, 2000.

[9] J. E. Vargas, "El Moko del plátano y banano y su manejo Institucional en el departamento del Quindío", en Memorias Seminario-Taller manejo integrado de la Sigatoka negra, Moko y Picudo negro del plátano, pp. 25-30, Armenia, Colombia, 2001.
[10] S. Belalcázar, F. Rosales, and L. Pocasangre, "El Moko del plátano y banano y el rol de las plantas hospederas en su epidemiología", XVI reunión internacional ACORBAT, pp. 16-35, Costa Rica, 2004.

[11] G. A. Granada, "Hospederos de Pseudomonas solanacearum Raza 2 en condiciones de la zona platanera del departamento del Quindío", en Tecnología del eje cafetero para la siembra y explotación rentable del cultivo del plátano, Comité Departamental de Cafeteros del Quindío, Armenia, Colombia, 1996.

[12] G. A. Granada, "Moko del plátano y banano en Colombia," Rev. Bananos y Plátanos, vol. 19, No.1, pp. 3943, Apr. 1997.

[13] G. A. Granada, "Manejo integrado del Moko (Ralstonia solanacearum Raza 2) en cultivos de banano y plátano," Centro de Investigaciones del Banano (Cenibanano). Boletín Técnico, vol. No.2, pp. 1-20, Apr. 2003.

[14] I.W. Buddenhagen, "Bacterial Soft Rot", en Compendium of tropical fruit diseases, G.A. Ploetz, R.C. Zentmyer, W.T. Nishijima, K.G. Rohrbach and H.D. Ohr, Ed. APS Press, 1994b.

[15] J. J. Castellanos, P. Oliva, E. Izquierdo, and N. Morales, "Evaluación de Bacillus subtilis como bio-control del patógeno Alternaria porri (Eli)". Cif en cebolla, Bioplag, p.95, INIFAT, La Habana, 1995.

[16] R. Schoalen, Manejo integrado de plagas en hortalizas. Segunda edición, Deusche Gesell's chaftf Technische Zusammenarbeit GTZ GmbH, 2006.

[17] E. Álvarez-Alcántara, A. Espigares-Rodríguez, and R. Gálvez-Vargas, "Valoración de desinfectantes. Método de dilución-neutralización," Higiene y Sanidad Ambiental, vol. 1, pp. 1-5, Apr. 2001.

[18] E. A. Gómez, E. Álvarez, and G. Llano, “Identificación y caracterización de cepas de Ralstonia solanacearum raza 2, agente causal del Moko de plátano en Colombia", Trabajo de grado, Facultad de Ciencias, Pontificia Universidad Javeriana, Bogotá, Colombia, 2005.

[19] M. L. Salgado, and Z. L. Faucikovsky, "Antagonismo in vitro de B. Subtilis sobre patógenos de frutales," Memoria de la Fundación Salvador Sanchez Colin. Cictamex S.C., pp. 189-192, 1994.

[20] J. Wu, S. Kang, B. Song, D. Hu, M. L. Jin, and S. Yang, "Synthesis and antibacterial activity against ralstonia solanacearum for novel hydrazone derivatives con taining a pyridine moiety," Chemistry Central J, vol. 6, pp. 26-28, Apr. 2012. 